\title{
GEOSPATIAL BASED CITIZEN CENTRIC WATER QUALITY MEASUREMENT SOLUTION
}

\author{
Kapil Oberai ${ }^{1,}{ }^{*}$, Suchit Purohit ${ }^{2}$, Prabhakar Alok Verma ${ }^{1}$, Aniruddha Deshmukh ${ }^{1}$, Sameer Saran ${ }^{1}$, Prakash Chauhan ${ }^{1}$ \\ ${ }^{1}$ Indian Institute of Remote Sensing, ISRO, Dehradun, India - (kapil, prabhakar, aniruddha, sameer, prakash)@iirs.gov.in \\ ${ }^{2}$ Department of Computer Science, Gujarat University, Ahmedabad, India - suchit.s.purohit@ieee.org
}

Commission V, WG V/3

KEY WORDS: Water Quality, Turbidity, Citizen Science, Geotagging, Mobile app, Web Based Dashboard, Open Source

\begin{abstract}
:
Citizen science has emerged as a game changer in various scientific endeavors, wherein scientific data for understanding the phenomenon could be collected by volunteers/non-specialist in a quick possible time. Citizens nowadays play an important role by functioning as "sensors" helping government/institutions by collecting and analyzing data. The advancements and convergence of technologies (Information and communication technologies (ICT)), especially the Internet and mobile technology has further assisted in such efforts. Moreover, the location sensors (GPS) and camera on board the mobile devices enables citizens to collect geotagged data. The classic example is the OpenStreetMap project where volunteers contribute towards the mapping of the planet. This paper highlights the geospatial solution based on citizen science to collect geotagged data about the water quality (turbidity). This solution is developed using open source tools and consists of an Android based mobile app and web based dashboard on the server side for real time data visualization and analysis. The web application is designed and developed using PHP, JavaScript, HTML \& CSS and allows user to view the interpolated geotagged data about water quality over various background maps like OSM, Bhuvan etc. PostgreSQL/PostGIS are used as the backend geospatial data server for storing the geotagged dataset. Such solution will be very useful for water quality monitoring as part of national level project like Clean Ganga Mission using the citizen centric approach.
\end{abstract}

\section{INTRODUCTION}

Collecting GIS data can be very expensive in terms of time as well as resources. But by distributing the data collection load to the volunteers can make process efficient and effective. Such process of involving citizens in the work is known as citizen science. There are a lot of successful projects of the citizen science based system like Wikimapia, OpenStreetMap etc. "Citizen science these days is a valuable and important method, in which non-specialists also called as volunteers work towards collection of data of scientific importance in a short span of time using the power of people/volunteers" (Oberai et. al, 2019). In the recent decade there has been explosion in the Internet, Android users. The functionalities available in the smartphones like GPS, camera, internet gives the GIS technology in the hand of citizens. Also the open source nature of operating system of smartphones allows the scientific community to develop citizen oriented applications to collect the Geotagged data. This data can be related to disaster, drought, crop health monitoring, water quality etc.

Recently Government of India has launched a clean Ganga mission with the objectives effective abatement of pollution, conservation and rejuvenation of National River Ganga (https://nmeg.nic.in). Mission with such objectives needs a lot of ground data which can be analysed later to identify the causative factors of pollution and accordingly preventive measure can be taken. There are many parameters to test the quality of water like biological oxygen demand, chemical oxygen demand, turbidity etc. Some of water quality parameters need specific instruments while some can be measured using indirect method or remote method like turbidity, chlorophyll content of the water.

Lloyd (1987) also suggested turbidity as the valid and useful quality measure of the water. What if the data is collected by citizens with simple app of smartphone? There is an android application named TurbidityMeter capable of calculating turbidity by clicking the photographs of the water, grey card and sky

Since turbidity is the continuous phenomenon, so turbidity value of the samples can be interpolated to get the surface map of the water quality. Interpolation is the technique to estimate value at the unsampled locations based on observations.

Interpolated map can be published on the web for visualization. There are a lot of open source tools available to perform this task.

\footnotetext{
${ }^{*}$ Corresponding author
} 


\section{STUDY AREA}

The study area (as shown in figure 1) taken for this technology demonstration is a part of Sahastradhara in Dehradun with the extent varying from $78.11^{\circ} \mathrm{E}$ to $78.13^{\circ} \mathrm{E}$ and $30.38^{\circ} \mathrm{N}$ to $30.39^{\circ} \mathrm{N}$.

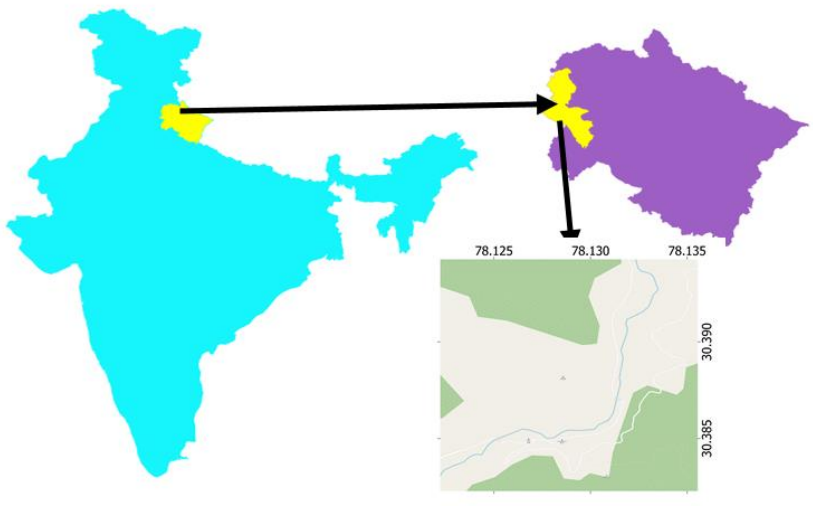

Figure 1: Study area

\section{METHODOLOGY}

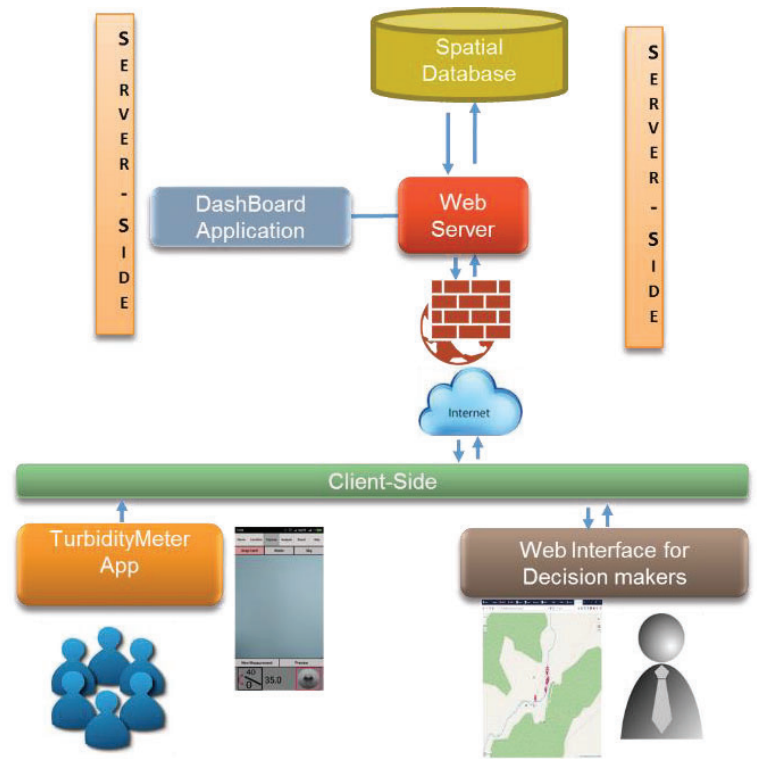

Figure 2: Methodology diagram

For this study, TurbidityMeter app was used to measure the water turbidity. This app is based on the reflectance properties of the water. App requires calibration before each reading, and this calibration is done with the help of known reflectance card, in this case grey card with $18 \%$ reflectance across the visible spectrum of light. Also calibration is done with open sky. After due calibration, image of the optically water can be captured. Optically deep water is taken so that image captured will not have reflectance value from the bottom of the water. Another basic requirement for this app is smartphone equipped with color camera, GPS, gyroscope. Color camera is used to capture the photograph of deep water in RGB channel. Other sensors like GPS is used to Geotag the reading, gyroscope is used to orient the phone in the correct position while taking the picture. There is one more similar kind of application named HydroColor (Leeuw, T. and Boss, E., 2018).

Principle behind calculating water reflectance is based on the equation given by Mobley, C.D., 1999.

$$
R_{\text {water }}=\frac{L 1-p L s}{\frac{\pi L c}{R_{\text {ref }}}}
$$

Where, $R_{\text {water }}$ is surface reflectance of water, $L 1$ stands for water surface leaving radiance, $L s$ is sky radiance, $R_{r e f}$ is reference reflectance i.e. grey card radiance in this case, $L c$ is the measured radiance leaving the standard i.e. grey card, $p$ sea surface reflectance factor.

Images should be taken at specific angle to minimize the surface reflectance (Mobley, C.D., 2015). In this case, sky image should be taken around $130^{\circ}$ nadir and $135^{\circ}$ solar azimuth. Similarly, grey card and water image to be taken at $40^{\circ}$ nadir and $135^{\circ}$ solar azimuth. App calculates Turbidity from the reflectance values based on the calibration from the known lab measurement in NTU as well as $\mathrm{mg} / \mathrm{l}$.

Point measurement values are interpolated to get the surface distribution of the turbidity across and along the river. Since river chosen for this study lies in the lap of lower Himalaya, so width of the river is very narrow. Hence best suited interpolation method in such scenario is spline technique which is based on the piecewise polynomial function. Although best suited method of interpolation in such undulating terrain of Himalaya is geostatistical method (Verma, P.A. et. al, 2019). But in our study area sampling location are distributed only along the river, hence autocorrelation function could not be fitted properly which is the basic requirement of the geostatistical techniques.

The water quality data collected using citizen science approach could be visualized in real-time using the web based dashboard. The web based dashboard application is designed and developed using PHP, JavaScript, HTML \& CSS and allows user to view the interpolated geotagged data about water quality over various background maps like OSM, Bhuvan etc. PostgreSQL/PostGIS (https://postgis.net/) are used as the backend geospatial data server for storing the geotagged dataset including the photographs. Open source Geoserver (http://geoserver.org/) was used as GIS server for publishing the spatial interpolated map along with the citizen collected data on the web. Open source Leaflet (https://leafletjs.com/) library was used for creating the web mapping interface. 


\section{RESULTS}
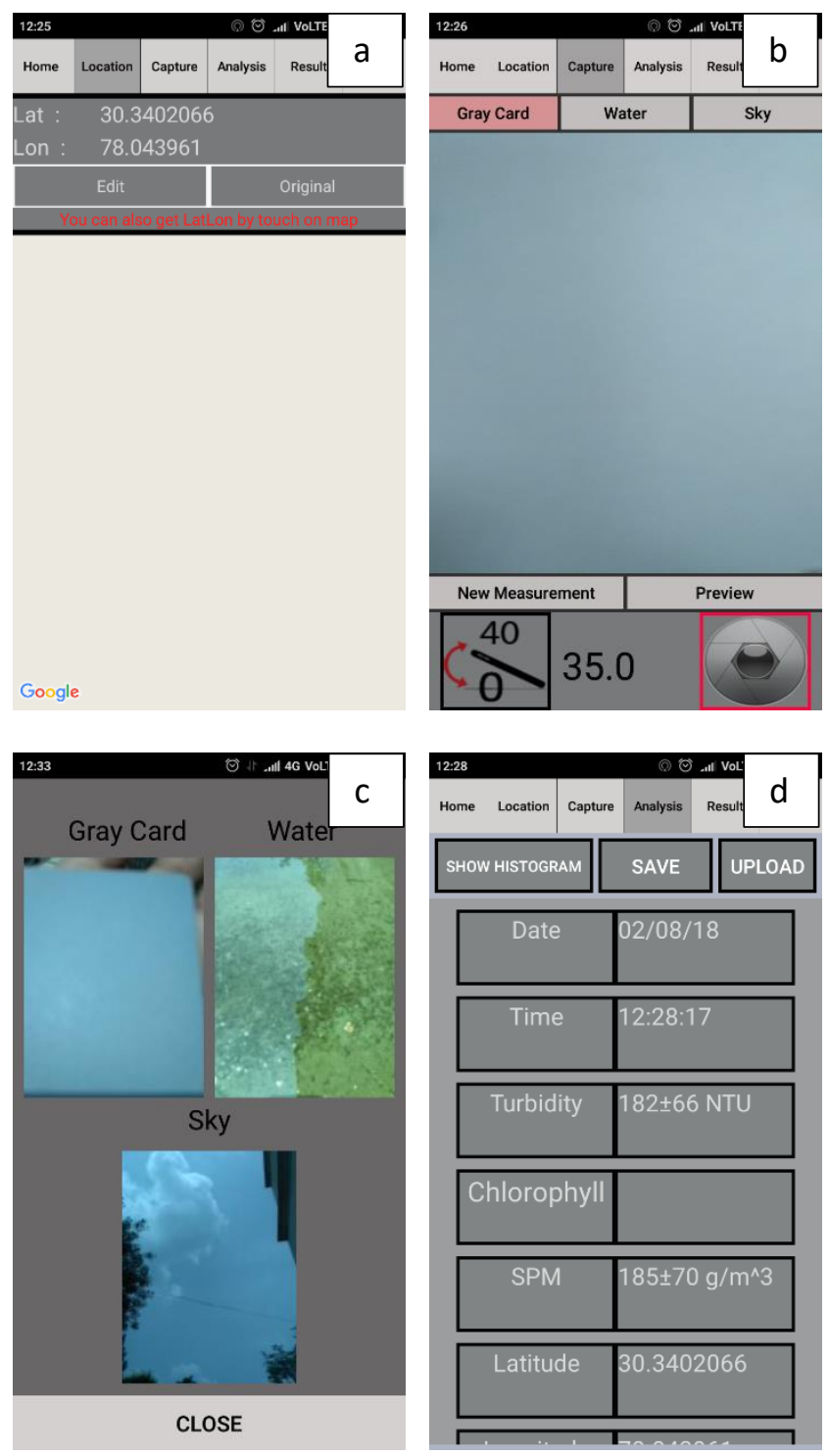

Figure 3: Screenshot of the app

In figure 3, picture a shows the location screen where location can be acquired from the smartphone inbuilt GPS by pressing 'Original' button or coordinate values can be entered in degree decimal format by pressing 'Edit' button. Picture $b$ shows the image of grey card, this screen assist user to tilt phone around $40^{\circ}$ using the inbuilt gyroscope sensor, as it can be seen picture is taken at $35^{\circ}$. If this angle is deviating more from $40^{\circ}$, the image capture button will not be highlighted. Picture $c$ shows the images of sky and water. After perform steps of pictures a, b, c turbidity calculation will appear under analysis tab as shown in picture $d$.
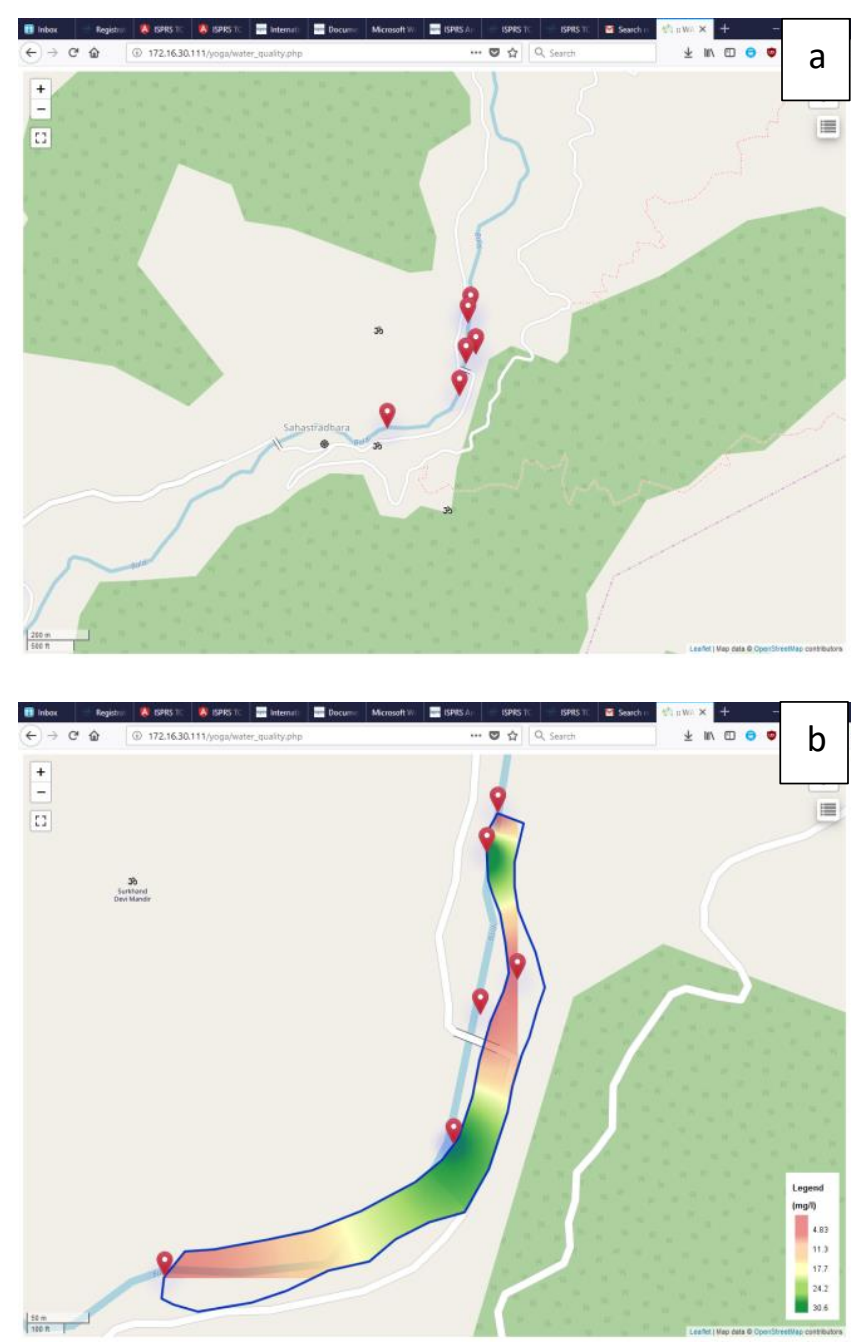

Figure 4: Dashboard for visualisation of interpolated turbidity

In figure 4, picture $a$ shows the dashboard where data can be easily visualized with different type of layers in background. Such kind of visualisation helps in deciding the hotspot location region of the polluted/ turbid water. Also visualisation with detailed land use map will give a quick idea about kind of anthropogenic activity responsible for the pollution.

As in figure 4 , picture $b$, it can be seen that turbidity ranges from 4 $\mathrm{mg} / \mathrm{l}$ to $30 \mathrm{mg} / \mathrm{l}$. And the highest values are measured at the bend of the river. Generally, turbidity can be higher at the sharp bends because of erosion due to fast flowing water. Also the higher turbidity can be seen on the top of picture $b$ of figure 4 . This may because of the anthropogenic activities. Actually this study area is small tourist place and people visit the top side of selected area. 


\section{CONCLUSION}

Anthropogenic activities are one of the major cause behind the polluted water of the rivers in India. To identify the anthropogenic activities, relation between the pollution level and activities need to be established. GIS gives the power to identify such relation more easily, but it requires geotagged data of the water quality. This system developed by us allows decision maker to visualize and anlayse water quality data in real time. Using this application, first objective of the clean ganga mission i.e. abatement of pollution can be achieved easily. It can be concluded that development of such kind of scientific applications has huge usage potential for the government as well as public.

\section{REFERENCES}

Lloyd, D.S., 1987. Turbidity as a water quality standard for salmonid habitats in Alaska. North American journal of fisheries management, 7(1), pp.34-45.

Leeuw, T. and Boss, E., 2018. The hydrocolor app: Above water measurements of remote sensing reflectance and turbidity using a smartphone camera. Sensors, 18(1), p.256.

Mobley, C.D., 1999. Estimation of the remote-sensing reflectance from above-surface measurements. Applied optics, 38(36), pp.7442-7455.

Mobley, C.D., 2015. Polarized reflectance and transmittance properties of windblown sea surfaces. Applied optics, 54(15), pp.4828-4849.

Oberai, K., Saran, S., Gupta, S., Singh, P., Srivastav, S.K. and Kumar, A.S., 2019. Role of Citizen Science in Northwestern Himalaya: Use Case on Disaster, Bio-resource, and Governance. In Remote Sensing of Northwest Himalayan Ecosystems (pp. 549564). Springer, Singapore.

Verma, P.A., Shankar, H. and Saran, S., 2019. Comparison of Geostatistical and Deterministic Interpolation to Derive Climatic Surfaces for Mountain Ecosystem. In Remote Sensing of Northwest Himalayan Ecosystems (pp. 537-547). Springer, Singapore.

https://nmeg.nic.in

accessed on October 3, 2018

https://postgis.net/

accessed on October 3, 2018

http://geoserver.org/

accessed on October 3, 2018

https://leafletjs.com/

accessed on October 3, 2018 